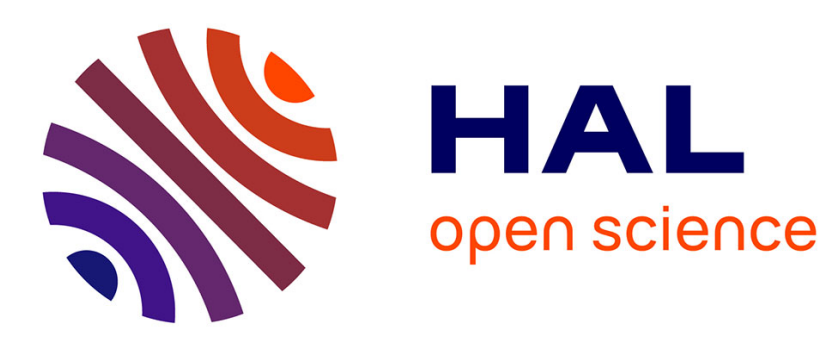

\title{
Non-consumptive effects of a top-predator decrease the strength of the trophic cascade in a four-level terrestrial food web
}

Elvire Bestion, Julien Cucherousset, Aimeric Teyssier, Julien Cote

\section{- To cite this version:}

Elvire Bestion, Julien Cucherousset, Aimeric Teyssier, Julien Cote. Non-consumptive effects of a toppredator decrease the strength of the trophic cascade in a four-level terrestrial food web. Oikos, 2015, 124 (12), pp.1597-1603. 10.1111/oik.02196 . hal-01628025

\section{HAL Id: hal-01628025 \\ https://hal.science/hal-01628025}

Submitted on 2 Nov 2017

HAL is a multi-disciplinary open access archive for the deposit and dissemination of scientific research documents, whether they are published or not. The documents may come from teaching and research institutions in France or abroad, or from public or private research centers.
L'archive ouverte pluridisciplinaire HAL, est destinée au dépôt et à la diffusion de documents scientifiques de niveau recherche, publiés ou non, émanant des établissements d'enseignement et de recherche français ou étrangers, des laboratoires publics ou privés. 
Non-consumptive effects of a top-predator decrease the strength of the trophic cascade in a four-level terrestrial food web

\section{Oikos, 2015, 124(12):1597-1603 doi: 10.1111/oik.02196}

Elvire Bestion ${ }^{* 1,3}$, Julien Cucherousset ${ }^{2,3}$, Aimeric Teyssier ${ }^{2,3,4}$, Julien Cote $*^{2,3}$

${ }^{1}$ CNRS USR 2936, Station d'Ecologie Expérimentale de Moulis, F-09200 Moulis, France

${ }^{2}$ CNRS UMR 5174, EDB (Laboratoire Evolution et Diversité Biologique), Toulouse, France

${ }^{3}$ Université de Toulouse UPS, 118 Route de Narbonne, Bât 4R1, 31062 Toulouse Cedex 9, France

${ }^{4}$ Terrestrial Ecology Unit, Ghent University, Ghent, Belgium

* Corresponding authors:

elvire.bestion@ecoex-moulis.cnrs.frfax: +33 5619608 51, julien.cote@univ-tlse3.fr 


\begin{abstract}
The fear of predators can strongly impact food web dynamics and ecosystem functioning through effects on herbivores morphology, physiology or behaviour. While non-consumptive predator effects have been mostly studied in three-level food chains, we lack evidence for the propagation of non-consumptive indirect effects of apex predators in four level food-webs, notably in terrestrial ecosystems. In experimental mesocosms, we manipulated a four-level food chain including top-predator cues (snakes), mesopredators (lizards), herbivores (crickets), and primary producers (plants). The strength of the trophic cascade induced by mesopredators through the consumption of herbivores decreased in the presence of toppredator cues. Specifically, primary production was higher in mesocosms where mesopredators were present relative to mesocosms with herbivores only, and this difference was reduced in presence of top-predator cues, probably through a trait-mediated effect on lizard foraging. Our study demonstrates that non-consumptive effects of predation risk can cascade down to affect both herbivores and plants in a four-level terrestrial food chain and emphasises the need to quantify the importance of such indirect effects in natural communities.
\end{abstract}




\section{Introduction}

While community studies have traditionally focused on consumptive effects of predators on their prey, evidence is growing on the non-consumptive effects caused by predators presence (Werner and Peacor 2003, Preisser et al. 2005). By affecting prey's morphology (Relyea 2000), behaviour (e.g. activity level, Wooster and Sih 1995; foraging effort, Verdolin 2006, or habitat use, Beckerman et al. 1997) or life-history traits (Benard 2004), the fear of predators can influence prey population dynamics and subsequently lower trophic levels (Schmitz et al. 2004). For instance, in an old-field food web, the presence of "risk spiders" (with their mouthparts glued to prevent feeding) increased grasshopper mortality and, consequently, plant biomass (Schmitz et al. 1997). Cascading effects of non-consumptive interactions are found in a wide variety of systems (Werner and Peacor 2003) and their consequences could be at least as important than those of consumptive interactions (Preisser et al. 2005). Indeed, some of the most famous examples of predator-prey interactions, like the lynx-hare population cycles (Krebs et al. 2001) or the trophic cascade between killer whales, sea otters and sea urchins (Estes et al. 1998), have been revisited and now believed to operate not solely trough consumption (Peckarsky et al. 2008) but also through intimidation and changes in prey's traits. Morevoer, non consumptive effects of predators can impact ecosystem functioning, for example by altering nutrient cycling rates (Schmitz et al. 2010).

Although such indirect effects of predation risk are well-studied in three-level food webs (see Schmitz et al. 2004 for a review), there is little evidence for longer food chains. Studies on non-consumptive effects are often limited to the lower levels of food chains, investigating the impact of mesopredators on herbivores and primary producers. However, mesopredators are themselves subjected to predation risk by top (or apex)-predators. Changes in top-predator presence often have disproportionate effects on mesopredators abundance through consumptive and non-consumptive effects (Ritchie and Johnson 2009). Hence, we could 
expect non-consumptive effects from top predators to have disproportionally strong impacts on the entire food chain. The scarcity of investigations focusing on higher food chain levels is therefore a concern, especially in the light of the unprecedented impacts of human activities on top predators (Estes et al. 2011, Ripple et al. 2014). Additionally, while many studies have focused on non-consumptive effects in aquatic systems (e.g. Trussel et al. 2004, Wada et al. 2013 in intertidal systems, Grabowski 2004, Wirsing et al. 2008 in marine systems, Pangle et al. 2007 in lakes, Bernot and Turner 2001, Peacor and Werner 1997, Wojdak and Luttbeg 2005 in ponds, Huang and Sih 1991, Peckarsky and McIntosh 1998, Majdi et al. 2014 in streams), our knowledge in terrestrial systems is less extensive (but see for example Beckerman et al. 1997, Schmitz 1998, Schmitz and Suttle 2001 in an old-field ecosystem, Rudgers et al. 2003 in a wild cotton system, or Pusenius and Ostfeld 2000 on stoats and meadow voles). Because there are strong functional differences between aquatic and terrestrial ecosystems (e.g. top-down controls strength: Shurin et al. 2002, degree of sizestructuring: Shurin et al. 2006, food web topology: Thompson et al. 2007), generalising across systems requires investigations on non-consumptive effects in a wide range of food web topologies and ecosystems.

Here we tested for the indirect consequences of top-predator presence on primary producers through their non-consumptive effects on mesopredators and their herbivorous prey in a fourlevel terrestrial experimental food chain. Non-consumptive and consumptive interactions are intrinsically linked, with predators often changing both prey behaviour and density (Preisser et al. 2005), therefore, their respective effects may be difficult to disentangle in the field. To explore the dynamics of non-consumptive effects from apex predators, we therefore used an experimental approach using similar taxa than the ones found together in natural communities and controlling for most environmental parameters (Bolker et al. 2003). Cues from a saurophagous snake were used to simulate the presence of a top-predator in mesocosms with 
lizards as mesopredators, crickets as herbivores and three plant species. We predicted (Fig. 1) that (1) mesopredators presence would decrease herbivore abundance and subsequently increase primary production through a trophic cascade; (2) top-predator cues would increase herbivore abundance through a non-consumptive effect on mesopredators and ultimately increase primary production through a decrease in the strength of the trophic cascade caused by mesopredators.

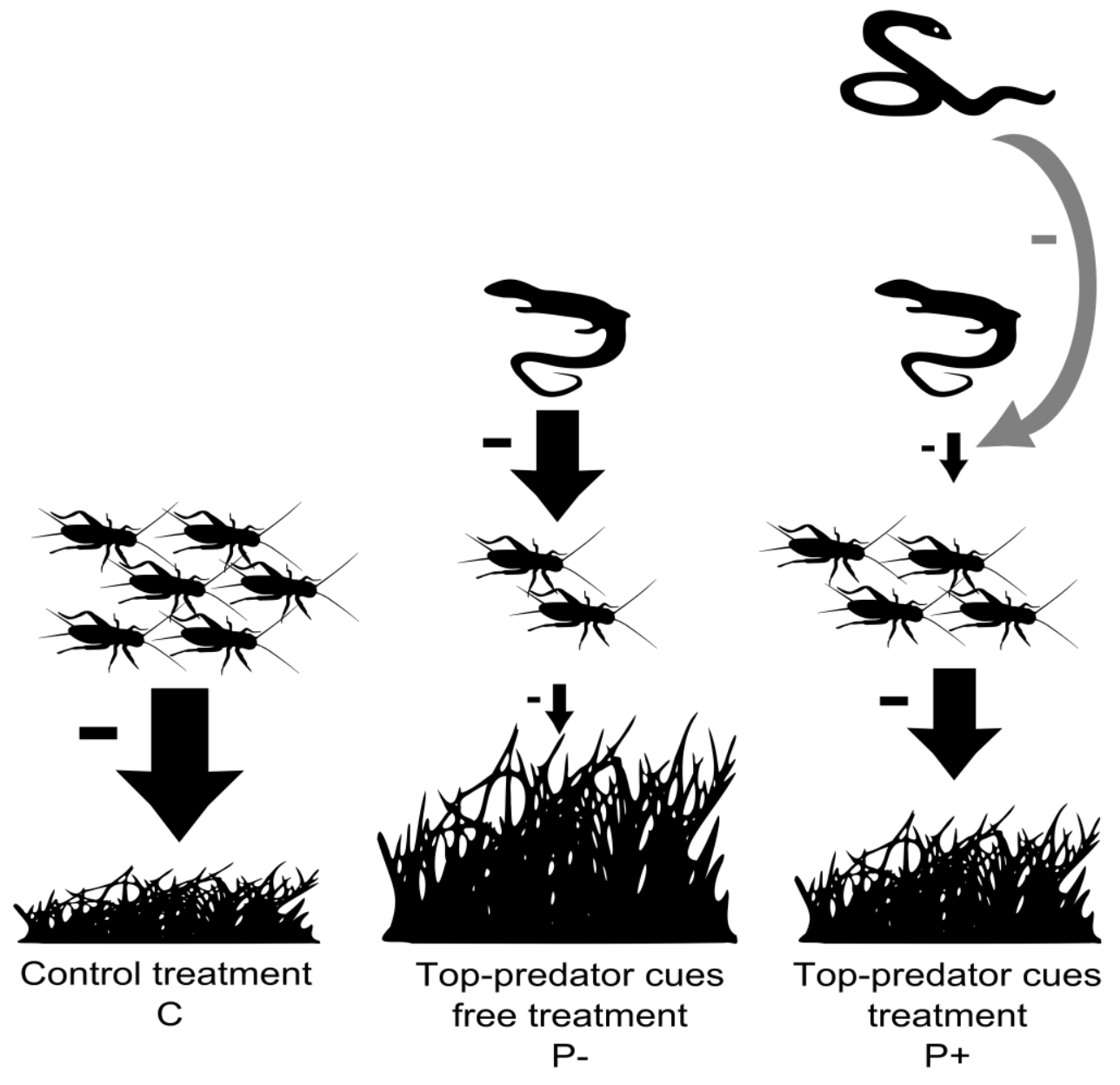

Figure 1: Flowchart of the experimental design and associated predictions. Solid arrows correspond to consumptive effects whereas dotted arrows represent non-consumptive effects. Arrow size represents the intensity of the effect. 


\section{Material and Methods}

A preliminary experiment was conducted in May 2012 to determine the effect of top-predator cues on lizard consumption without considering the subsequent effects on lower trophic levels (see methods in Supplementary Material S1). The main experiment, conducted in September 2012, aimed at determining the non-consumptive effects of top-predator cues on a four-level food chain composed of three primary producers (English ryegrass Lolium perenne L., alfalfa Medicago sativa and clover Trifolium pratense L.), herbivores (crickets Acheta domesticus), mesopredators (common lizards Zootoca vivipara) and top-predators (green whip snakes Hierophis viridiflavus) using a simplified food chain that was, however, realistic with regard to the densities and taxa observed in wild populations. These plant and herbivore taxa were selected because they are similar to those found in natural communities from habitats of 18 lizards populations (Ardeche, France, $44^{\circ} 40^{\prime} \mathrm{N}, 04^{\circ} 10^{\prime} \mathrm{E}$, see details below). The experiment included 12 mesocosms: 4 with lizards and top-predator cues ( $\mathrm{P}+$, four-level food-webs), 4 with lizards and without top-predator cues (P-, three-level food-webs), and 4 control mesocosms without lizards (C, two-level food-webs, 2 with top-predator cues and 2 without top-predator cues, Fig. 1). Mesocosms consisted of $1000 \mathrm{~L}$ cattle tanks (Ø $1.7 \mathrm{~m})$ filled with gravel and $110 \mathrm{~L}$ of soil litter and covered with an insect-proof net. We provided 2 water dishes, shelters (1 brick, 4 half-flower pots and 5 falcon tubes) and thermoregulation spots (rocks and logs) for lizards, and one shelter for crickets (1 plastic pot with perforations allowing only crickets entrance). Twelve mesocosms (6 with and 6 without top-predator cues) were placed outside in an open-field sunny area and were disposed so that the average distance between mesocosms of the same treatment was $4 \mathrm{~m}(2.7 \mathrm{~m}-6 \mathrm{~m})$. Mesocosms of the top-predator cues treatment were separated by mesocosms of the without top-predator cues treatment by $4 \mathrm{~m}$, ensuring that there was no contamination. 


\section{Primary producers}

A Poaceae species (English ryegrass) and two Fabaceae species (alfalfa and clover) were selected as primary producers because they are commonly found in common lizards habitats, and more generally in grassland habitats. They also represent an important resource for many herbivorous species (Kirwan et al. 2007). In 18 lizard populations, we performed three 20-m long transects with 100 recording points (i.e. every $20 \mathrm{~cm}$ ). The herbaceous stratum was composed of 33 plant families. Overall, Poaceae and Fabaceae families were the $1^{\text {st }}$ and the $5^{\text {th }}$ most abundant families and were present in 18 and 16 of the monitored populations, respectively. We selected commercially available species of these two families to control for seed size and quality. For the experiment, each mesocosm contained 2 patches of ryegrass, 1 patch of alfalfa and 1 patch of clover grown from seeds $(0.5,0.2$ and $0.2 \mathrm{~g}$ of seeds respectively) in large plastic dishes for ryegrass $(\varnothing 30 \mathrm{~cm} \times 5 \mathrm{~cm})$, and in small terraria for alfalfa and clover $(18 \times 12 \times 11 \mathrm{~cm})$ for 3 weeks before the beginning of the experiment. One extra patch for each plant species was used to measure dry mass at the beginning of the experiment. At the start of experiment, we determined the number of blades of grass for each patch and found no significant differences $\left(\mathrm{F}_{2,9}<0.24, \mathrm{p}>0.79\right.$ for all plant types $)$.

\section{Herbivores}

Common lizard, our mesopredator species, is a generalist species and its preferred prey are Araneae, Homoptera, Heteroptera and Orthoptera (Avery 1966, González-Suárez et al. 2011). In each of the 18 wild populations of lizards we monitored, three pitfall traps, filled with ethanol (30\%), were left for four days. Insects were then collected and determined. Orthoptera, Homoptera and Heteroptera each represented $20 \%$ of the collected arthropods; Araneaee being the most abundant group (i.e. 40\%). These four taxonomic groups were present in all populations. For the experiment, the selected herbivores were house crickets, 
Orthoptera of the Grillidae family that occur throughout Europe. They are mostly herbivorous, however they can display opportunistic foraging behaviour, and can easily be found in large quantities commercially. We introduced 340 commercially-reared crickets per mesocosm. The number was chosen to match lizard consumption rates (Avery 1971, see Supplementary Material S2). Half of the crickets were introduced at the beginning of the experiment and half after two weeks, to prevent excessive mortality during the experiment as cricket life-span is relatively short (Lyn et al. 2012) and to mimic cricket immigration into the mesocosms. Cricket size was standardised and cricket mass did not differ significantly between treatments (cricket mass: $0.061 \mathrm{~g} \pm 0.001 \mathrm{SD} ; \mathrm{F}_{2,9}=0.207, \mathrm{p}=0.82$ ).

\section{Mesopredators}

Our mesopredator species was the common lizard (Zootoca vivipara), a small (adult snoutvent length 40-70 mm) ground-dwelling lizard inhabiting dense grassland habitats in Eurasia. Fifty adult male common lizards caught from wild populations in June 2012 (Ardeche, France, $\left.44^{\circ} 40^{\prime} \mathrm{N}, 04^{\circ} 10^{\prime} \mathrm{E}\right)$ were maintained individually until the beginning of the experiment (see Bestion et al. 2014 for maintenance details). We used males only to avoid any mating interactions during the experiment. A total of 32 adult male lizards was used for the experiment with 4 lizards in each inhabited mesocosm. In this species, individuals commonly share resources such as basking spots and night refuges. Although population density can be low at a large scale, our monitoring of local densities in natural populations varied between 0 and 12 individuals per $\mathrm{m}^{2}$ with on average $2.7 \pm 2.3 \mathrm{SE}$ individuals per $\mathrm{m}^{2}$. Therefore, the density used in this experiment (1.7 individuals per $\left.\mathrm{m}^{2}\right)$ was in the range of values observed in wild populations. Lizards snout-vent length, total size and body mass did not differ significantly between treatments (resp. $\mathrm{F}_{1,31}=0.19, \mathrm{p}=0.67 ; \mathrm{F}_{1,31}=0.07, \mathrm{p}=0.79 ; \mathrm{F}_{1,31}=$ 0.001, $\mathrm{p}=0.97)$. During the experiment, one lizard from $\mathrm{P}+$ died and was immediately replaced. 


\section{Top-predator cues}

Top-predator cues were collected from two adult green whip snakes caught from the wild and maintained in the lab (see Bestion et al. 2014 for maintenance details). Green whip snakes are generalist feeders, preying upon small mammals, reptiles and birds, with reptiles accounting for nearly $20 \%$ of their diet in the wild (Lelièvre et al. 2012). We placed 40 calcite tiles ( $3 \times 3$ $\mathrm{x} 0.6 \mathrm{~cm}$ ) into the snake cage. Tiles were left for $5 \pm 1$ days allowing the snake to leave olfactory cues. Tiles were hence collected and rubbed on the snake belly to saturate them with odour before placing them into the mesocosms (Bestion et al. 2014, Teyssier et al. 2014). Forty tiles kept in a separate room were used as controls for the mesocosms without toppredator cues. Eight tiles were used in each mesocosm on a roll-over schedule ( 5 days in the snake cage, 5 days in the mesocosms). As predator cues were left in the mesocosms for roughly 5 days depending on the weather before changing them, the mesocosms were not constantly saturated with predator cues and our treatments simulates the presence of predators in the habitat rather than immediate predation risk. In our previous studies, this procedure was efficient in inducing behavioural and morphological modifications, considered as classical antipredator defences (Teyssier et al. 2014, Bestion et al. 2014).

\section{Mesocosms monitoring and data collection}

The experiment lasted 30 days (September $1^{\text {st }}$ to September $30^{\text {th }} 2012$ ), with mesocosms being watered twice a day without removing the nets and odour cues changed every 5 days after removing the nets. At the end of the experiment, crickets were collected and counted. Plant patches were removed and the aerial parts were cut. All samples (crickets and plant aerial parts) were then oven dried for 72 hours at $65^{\circ} \mathrm{C}$ and weighted for dry mass. Plant dry mass was summed over the four plant patches. Total primary production was the difference 
between plant dry masses of at the end of the experiment and at the beginning of the experiment (reference patches).

\section{Statistical analyses}

We first checked whether control with top-predator cues and control without top-predator cues differed as this would have indicated that top-predator cues had an effect on the final biomass of herbivores and of primary producers. As there were no differences (cricket abundance: $54.5 \pm 0.5$ and $52.5 \pm 9.5$; total primary production: $11.6 \pm 0.6$ and $11.9 \pm 1.3 \mathrm{~g}$ in controls with and without top-predator cues, respectively), the two control groups were treated as a unique control in subsequent analyses. ANOVAs were performed to compare total primary production and abundance and the dry mass of crickets between treatments (i.e., C: control, P+: with top-predator cues and P-: without top-predator cues). Planned contrasts were subsequently used to test for the effect of lizard presence (control treatment compared to both with top-predator cues and without top-predator cues treatments) and the effect of toppredator cues treatment (treatment with top-predator cues compared to without treatment toppredator cues) on herbivore abundance and biomass and on primary production. Finally, a Spearman's rank correlation test was used to examine whether total primary production was correlated to the abundance of crickets at the end of the experiment. All statistical analyses were performed with R software, v2.15.2 (R Core Team 2012).

\section{Results}

At the end of the preliminary experiment, herbivore abundance was significantly higher with top-predator cues than without top-predator cues $\left(\mathrm{F}_{1,4}=128, \mathrm{p}<0.001\right.$; Fig. 2$)$. In the main experiment, herbivore abundance and dry mass differed significantly among treatments (ANOVA, $\mathrm{F}_{2,9}=18.2, \mathrm{p}<0.001 ; \mathrm{F}_{2,9}=11.1, \mathrm{p}=0.004$ respectively), with significantly more herbivores in control treatment than in both treatments with mesopredators. Herbivores tended 
to be less abundant in treatment without top-predator cues compared to treatment with toppredator cues but this difference was, however, not significant (Table 1, Fig. 2).

Table 1: Treatment effect on herbivores final abundance and dry mass and on total primary production. Results of the planned contrasts on the ANOVAs computing the effect of the treatment.

\section{Estimate SE t-value p-value}

\section{Contrast between lizard and lizard-free treatment}

Herbivore abundance

Herbivore dry mass

Total primary production $\begin{array}{llll}-29.00 & 5.00 & -5.84 & <0.001\end{array}$

$\begin{array}{llll}-0.36 & 0.08 & -4.50 & 0.001\end{array}$

$\begin{array}{llll}4.01 & 0.63 & 6.40 & <0.001\end{array}$

\section{Contrast between treatment with top-predator cues and treatment without top-predator cues}

Herbivore abundance

Herbivore dry mass

Total primary production $\begin{array}{llll}6.50 & 4.30 & 1.51 \quad 0.165\end{array}$

$\begin{array}{llll}0.10 & 0.07 & 1.43 & 0.187\end{array}$

$\begin{array}{llll}-1.75 & 0.54 & -3.22 & 0.010\end{array}$ 


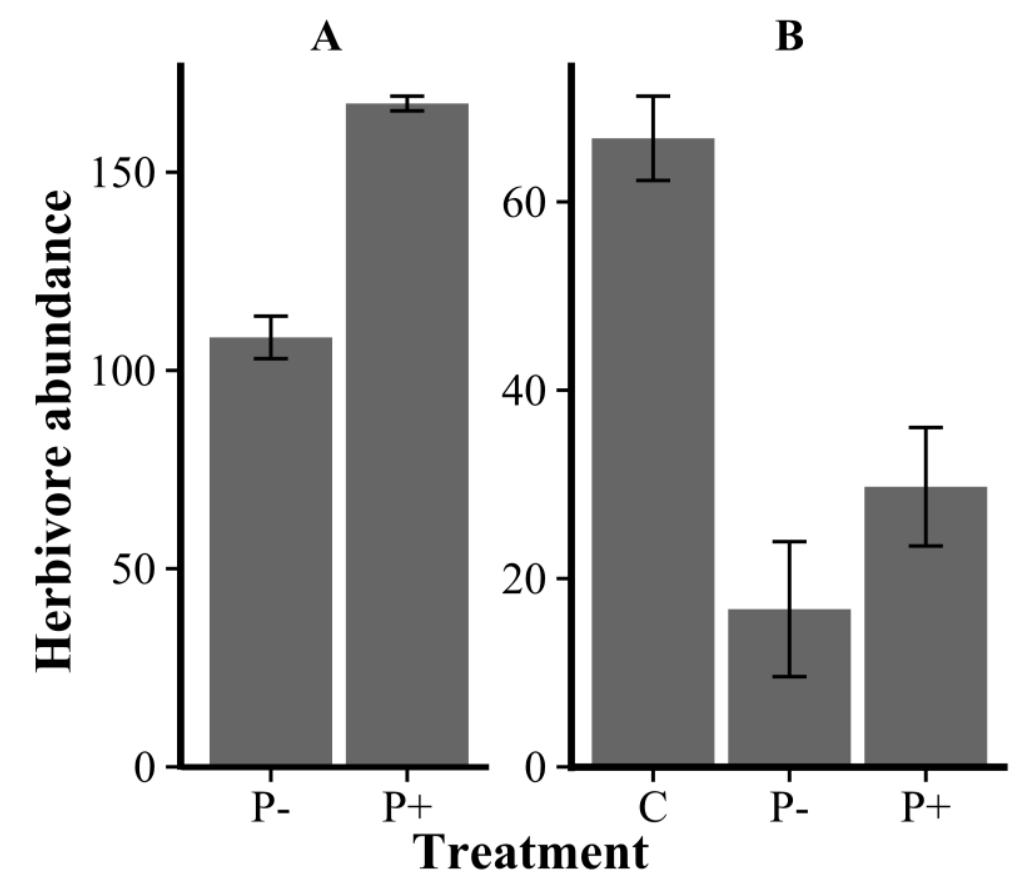

Figure 2: Herbivore abundance (number of crickets $\pm S E$ ) in each treatment at the end of preliminary $(A)$ and main $(B)$ experiments. Treatments include control without lizards $(C)$, with lizards and without top-predator cues $(P-)$, and with lizards and top-predator cues $(P+)$.

Primary production significantly differed between treatments $\left(\mathrm{F}_{2,9}=25.7, \mathrm{p}<0.001\right)$ and was negatively correlated to final herbivore abundance (Spearman's rank correlation, rho $=-0.71$, $\mathrm{p}=0.01)$. Primary production was significantly lower in control treatment than in treatments with mesopredators and in treatment with top-predator cues than in treatment without toppredator cues (Table 1, Fig. 3). 


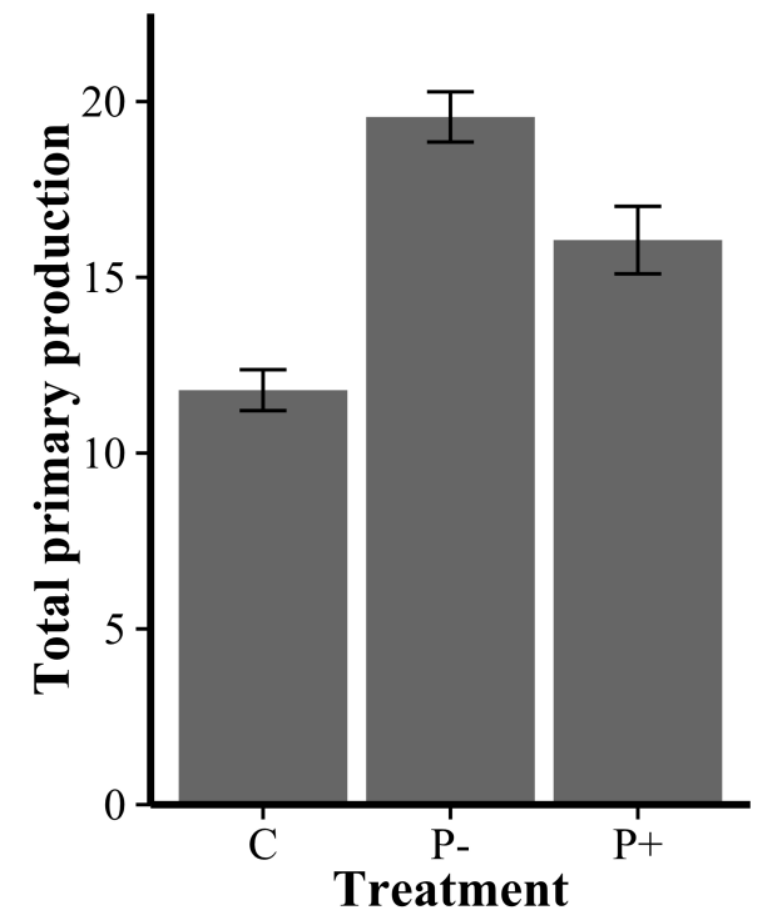

Figure 3: Total primary production (grams of dry matter $\pm S E$ ) in the four patches of plant for each treatment. Treatments include control without lizards $(C)$, with lizards and without top-predator cues (P-), and with lizards and top-predator cues $(P+)$.

\section{Discussion}

Our experimental study first demonstrated that primary production was increased in presence of mesopredators. This effect was likely mediated by the observed consumptive effects of mesopredators on herbivores and of herbivores on plants. Additionally, non-consumptive effects of mesopredators presence on herbivore behaviour (Adamo et al. 2013) could also have impacted this trophic cascade.

Moreover, primary production was lower in mesocosms with top-predators cues than in mesocosms without top-predator cues. When comparing primary production between mesocosms with or without top-predator cues to control mesocosms, the intensity of the trophic cascade caused by mesopredators appeared dampened in mesocosms with top- 
predator cues. This effect was most likely explained by a variation in mesopredators consumption of herbivores in presence of top-predator cues, subsequently affecting herbivores consumption of plants. Indeed, predation risk decreases activity (Preisser et al. 2005) and foraging effort (Verdolin 2006) in a large range of species. Because lizards exposed to snake predator cues reduce their activity (Van Damme et al. 1995, Teyssier et al. 2014), this could subsequently diminish food consumption. Our preliminary experiment demonstrated indeed a strong decrease in lizard consumption of crickets in presence of top-predator cues. This effect was however weaker in the main experiment which might be explained by the way we manipulated herbivores abundances in the two experiments. In the main experiment, we released 340 crickets in two batches. Differences in prey density between treatments may have shrunken during the course of the experiment because cricket population size declined drastically as suggested by the final number of crickets. On the contrary, in the preliminary experiment, 100 crickets were added weekly keeping cricket density higher and allowing nonconsumptive effects of top-predators on lizard's prey consumption to be maintained. Alternatively, crickets might have responded to lizard foraging behaviour changes in presence of top-predator cues by changing their behaviour and food consumption (Adamo et al. 2013), with subsequent consequences on primary production. Primary production was however negatively correlated to the number of crickets remaining at the end of the experiment, making the consumption of crickets the most likely explanation for the differences in primary production between treatments with and without top-predator cues.

Our experimental mesocosms represented simplified food webs (one representative species from each trophic level, with the exception of primary producers), which could underestimate the potential complexity of interactions arising within trophic levels in natural communities. For instance, the strength of non-consumptive effects in food webs with diverse mesopredators might be modified. Indeed, the diet of green whip snakes, our top-predator 
species, is composed of several species of small reptiles and mammals (Lelièvre et al. 2012). As these prey species are almost all insectivorous, we could expect stronger non-consumptive effects of top-predator presence in food webs with multiple mesopredators. Predictions are however more complex when considering several species at lower trophic levels. We could expect non-consumptive effects of top-predators to cascade down more easily to primary producers when mesopredators are more specialized on herbivorous species, although this remains to be tested. Furthermore, propagation of top-down effects of predators could depend on plant palatability and nutrient content (Cebrian 1999). The plants used in this experiment were all highly palatable plants to most generalist herbivores. It is likely that outcomes would have been different in communities made of plants varying for their palatability and nutrient content. For the example, the fear of predators could lead herbivores to to shift their diet towards more energetic plants, e.g. higher carbohydrate-C content (Hawlena and Schmitz 2010), changing competitive interactions between plant species.

Our experimental study demonstrated the existence of non-consumptive effects of toppredator cues on primary production through a four-level cascade. This effect was likely mediated by a behavioural effect on lizard foraging behaviour. Previous studies found evidence of non-consumptive effects of mesopredators on prey and their resources in threelevel systems (Schmitz et al. 2004, Rudgers et al. 2003). The present results add to these studies by showing the first experimental evidence, to our knowledge, of a cascading impact of top-predator cues on primary production in a four-level, simplified, terrestrial food chain. Future studies are now needed to test for non-consumptive effects of top-predators in more complex systems, adding notably competition and predation at different trophic levels 


\section{Acknowledgements}

Thanks to Julie Siracusa, Julie Raphalen, Cyrille Camuel, Alexis Rutschmann, Antoine Lecerf for assistance or comments. We thank Alexis Rutschmann and Sylvain Moulherat for field survey data in the Cévennes. This work was supported by the French Laboratory of

Excellence project "TULIP" (ANR-10-LABX-41 ; ANR-11-IDEX-0002-02) and an ANR-12JSV7-0004-01 to JCo.

\section{References}

Adamo, S. A. et al. 2013. The behavioural effects of predator-induced stress responses in the cricket (Gryllus texensis): the upside of the stress response. - J. Exp. Biol. 216: 4608 4614.

Avery, R. A. 1966. Food and feeding habits of the Common lizard (Lacerta vivipara) in the west of England. - J. Zool. 149: 115-121.

Avery, R. A. 1971. Estimates of Food Consumption by the Lizard Lacerta vivipara Jacquin. J. Anim. Ecol. 40: 351-365.

Beckerman, A. P. et al. 1997. Experimental evidence for a behavior-mediated trophic cascade in a terrestrial food chain. - Proc. Natl. Acad. Sci. 94: 10735-10738.

Benard, M. F. 2004. Predator-Induced Phenotypic Plasticity in Organisms with Complex Life Histories. - Annu. Rev. Ecol. Evol. Syst. 35: 651-673.

Bernot, R. J. and Turner, A. M. 2001. Predator identity and trait-mediated indirect effects in a littoral food web. - Oecologia 129: 139-146.

Bestion, E. et al. 2014. Maternal exposure to predator scents: offspring phenotypic adjustment and dispersal. - Proc. R. Soc. B Biol. Sci. 281: 20140701.

Bolker, B. et al. 2003. Connecting theoretical and empirical studies of trait-mediated interactions. - Ecology 84: 1101-1114.

Cebrian, J. 1999. Patterns in the Fate of Production in Plant Communities. - Am. Nat. 154: 449-468.

Estes, J. A. et al. 1998. Killer Whale Predation on Sea Otters Linking Oceanic and Nearshore Ecosystems. - Science 282: 473-476.

Estes, J. A. et al. 2011. Trophic Downgrading of Planet Earth. - Science 333: 301-306.

González-Suárez, M. et al. 2011. Population and Life-History Consequences of WithinCohort Individual Variation. - Am. Nat. 178: 525-537. 
Grabowski, J. H. 2004. Habitat complexity disrupts predator-prey interactions but not the trophic cascade on oyster reefs. - Ecology 85: 995-1004.

Hawlena, D. and Schmitz, O. J. 2010. Herbivore physiological response to predation risk and implications for ecosystem nutrient dynamics. - Proc. Natl. Acad. Sci. 107: 1550315507.

Huang, C. and Sih, A. 1991. Experimental studies on direct and indirect interactions in a three trophic-level stream system. - Oecologia 85: 530-536.

Kirwan, L. et al. 2007. Evenness drives consistent diversity effects in intensive grassland systems across 28 European sites. - J. Ecol. 95: 530-539.

Krebs, C. J. et al. 2001. What Drives the 10-year Cycle of Snowshoe Hares? - BioScience 51: $25-35$.

Lelièvre, H. et al. 2012. Trophic niche overlap in two syntopic colubrid snakes (Hierophis viridiflavus and Zamenis longissimus) with contrasted lifestyles. - Amphib.-Reptil. 33: $37-44$.

Lyn, J. et al. 2012. Life History Features and Aging Rates: Insights from Intra-specific Patterns in the Cricket Acheta domesticus. - Evol. Biol. 39: 371-387.

Majdi, N. et al. 2014. Predator effects on a detritus-based food web are primarily mediated by non-trophic interactions (V Rudolf, Ed.). - J. Anim. Ecol.: n/a-n/a.

Pangle, K. L. et al. 2007. Large nonlethal effects of an invasive invertebrate predator on zooplankton population growth rate. - Ecology 88: 402-412.

Peacor, S. D. and Werner, E. E. 1997. Trait-mediated indirect interactions in a simple aquatic food web. - Ecology 78(4): 1146-1156.

Peckarsky, B. L. and McIntosh, A. R. 1998. Fitness and community consequences of avoiding multiple predators. - Oecologia 113: 565-576.

Peckarsky, B. L. et al. 2008. Revisiting the classics: considering nonconsumptive effects in textbook examples of predator-prey interactions. - Ecology 89: 2416-2425.

Preisser, E. L. et al. 2005. Scared to death? the effects of intimidation and consumption in predator-prey interactions. - Ecology 86: 501-509.

Pusenius, J. and Ostfeld, R. S. 2000. Effects of stoat's presence and auditory cues indicating its presence on tree seedling predation by meadow voles. - Oikos 91: 123-130.

R Core Team 2012. R: A Language and Environment for Statistical Computing. - R Foundation for Statistical Computing.

Relyea, R. A. 2000. Trait-mediated indirect effects in larval anurans: reversing competition with the threat of predation. - Ecology 81(8): 2278-2289.

Ripple, W. J. et al. 2014. Status and Ecological Effects of the World's Largest Carnivores. Science 343: 1241484. 
Ritchie, E. G. and Johnson, C. N. 2009. Predator interactions, mesopredator release and biodiversity conservation. - Ecol. Lett. 12: 982-998.

Rudgers, J. A. et al. 2003. Behavioral mechanisms underlie an ant-plant mutualism. Oecologia 135: 51-59.

Schmitz, O. J. 1998. Direct and Indirect Effects of Predation and Predation Risk in Old-Field Interaction Webs. - Am. Nat. 151: 327-342.

Schmitz, O. J. and Suttle, K. B. 2001. Effects of top predator species on direct and indirect interactions in a food web. - Ecology 82: 2072-2081.

Schmitz, O. J. et al. 1997. Behaviorally mediated trophic cascades: effects of predation risk on food web interactions. - Ecology 78: 1388-1399.

Schmitz, O. J. et al. 2004. Trophic cascades: The primacy of trait-mediated indirect interactions. - Ecol. Lett. 7: 153-163.

Schmitz, O. J. et al. 2010. Predator control of ecosystem nutrient dynamics. - Ecol. Lett. 13: 1199-1209.

Shurin, J. B. et al. 2002. A cross-ecosystem comparison of the strength of trophic cascades. Ecol. Lett. 5: 785-791.

Shurin, J. B. et al. 2006. All wet or dried up? Real differences between aquatic and terrestrial food webs. - Proc. R. Soc. B Biol. Sci. 273: 1-9.

Teyssier, A. et al. 2014. Partners' personality types and mate preferences: predation risk matters. - Behav. Ecol. 25: 723-733.

Thompson, R. M. et al. 2007. Trophic levels and trophic tangles: the prevalence of omnivory in real food webs. - Ecology 88: 612-617.

Trussel, G. C. et al. 2004. Trophic cascades in rocky shore tide pools: distinguishing lethal and nonlethal effects. - Oecologia 139: 427-432.

Van Damme, R. et al. 1995. Responses of Naive Lizards to Predator Chemical Cues. - J. Herpetol. 29: 38.

Verdolin, J. L. 2006. Meta-analysis of foraging and predation risk trade-offs in terrestrial systems. - Behav. Ecol. Sociobiol. 60: 457-464.

Wada, Y. et al. 2013. Changes in algal community structure via density- and trait-mediated indirect interactions in a marine ecosystem. - Ecology 94: 2567-2574.

Werner, E. E. and Peacor, S. D. 2003. A review of trait-mediated indirect interactions in ecological communities. - Ecology 84: 1083-1100.

Wirsing, A. J. et al. 2008. Seascapes of fear: evaluating sublethal predator effects experienced and generated by marine mammals. - Mar. Mammal Sci. 24: 1-15. 
Wojdak, J. M. and Luttbeg, B. 2005. Relative strengths of trait-mediated and densitymediated indirect effects of a predator vary with resource levels in a freshwater food chain. - Oikos 111: 592-598.

Wooster, D. and Sih, A. 1995. A Review of the Drift and Activity Responses of Stream Prey to Predator Presence. - Oikos 73: 3-8. 